\title{
Long-term follow-up of intraocular lens implants: the first 127 compared with the latest 100 of the same style in a span of 9 years
}

\author{
M. NOBLE,' H. CHENG,' P. JACOBS, ' J. SALMON, ${ }^{2}$ and K. MCPHERSON ${ }^{3}$ \\ From the 'Eye Hospital, Walton Street, Oxford; the ${ }^{2}$ Kent and Sussex Hospital, Tunbridge Wells, Kent, \\ and the Radcliffe Infirmary, Oxford
}

SUMmaRY The long-term follow up of the first 127 patients (127 eyes) treated by one surgeon with cataract extraction and Federov I lens implantation is reported. The proportion of patients achieving visual acuity of $6 / 12$ or better had decreased since the one year follow-up. Corneal oedema was the most serious long-term complication. This group of patients is compared with the latest 100 patients (100 eyes) operated on by the same surgeon using the same type of implant. There was a reduction of some operative complications, and improvement in surgical techniques had resulted in a lower sample endothelial cell loss at one month.

The late complications of intraocular lens surgery can be ascertained only by long-term studies with minimal loss to follow-up. While many studies have yielded short-term results, there are few with a minimum follow-up of 5 years. ${ }^{12}$

The purpose of this paper is to report: (1) the long-term results of a group of patients who received iris-clip lens implants, with a minimum follow-up of 5 years (group I); and (2) to compare the operative and perioperative complications and the visual outcome of these patients with those in a similar group (group II) who received basically the same lens type but who were operated on more recently and with revised techniques. By making such a comparison the effect of the change in technique can be evaluated without the confounding variable of a change in lens design.

\section{Materials and methods}

\section{PATIENTS}

Group I consisted of the first 127 consecutive patients treated by one surgeon (H.C.) with an intracapsular lens extraction followed by the insertion of a Federov I iris-clip lens. The treatment period was from October 1973 to August 1977. The mean age of patients at the time of surgery was 73 years (range 50 to 86 years).

Correspondence to Mr H. Cheng, FRCS, Eye Hospital, Walton Street, Oxford OX2 6AN.
Intravenous mannitol was given preoperatively to patients aged under 65 years. Surgery was performed under general anaesthesia, usually with assisted ventilation. The method of microsurgery was similar in each case. A $160^{\circ}$ to $180^{\circ}$ section was made after fashioning a limbal-based conjunctival flap. All cases received alpha-chymotrypsin and were treated by cryoextraction. Lens insertion was by means of a direct glide, with the section lifted. Care was taken to avoid endothelial touch where possible. In a further 6 patients operated on during this period loss of vitreous prevented lens implantation. They were not included in the study.

Group II consisted of the last 100 consecutive patients treated by the same surgeon with intracapsular lens extraction and Federov I lens implantation. The treatment period was from January 1978 to December 1982. The mean age at the time of surgery was 72 years (range 55 to 89 years).

In this group the preoperative preparation and anaesthetic were unchanged. The techniques of making the section and extracting the lens were similar to those in group I, but the length of the section was shortened to about $140^{\circ}$. After cryoextraction the section was loosely tied to maintain a closed anterior chamber, and the implant was inserted by sliding under an air bubble after it had first been coated with the patient's serum. ${ }^{3}$ If air was not retained during attempted insertion, the procedure 
Fig. 1 Federov I iris-clip lens with fixation peg.

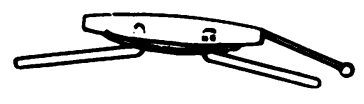

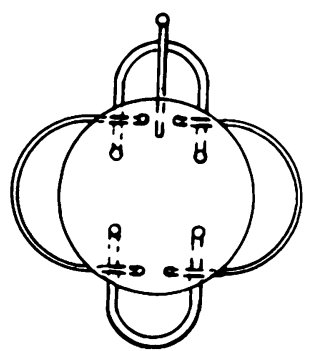

was abandoned, and the patient was not included in this group. Three eyes did not receive implants because of bulgy vitreous, but no eye was excluded from group II because of vitreous loss. Iridectomy was performed after insertion of the implant. The number of iridectomies was increased from one in group I to 2 in group II.

IMPLANT STYLE

All patients received a Federov I iris-clip implant or its variant with a transiridotomy peg (Fig. 1). The majority of patients in group I received lenses without a peg. Of these about half had one of the anterior lens loops sutured to the iris stroma at 11 o'clock after the lens had been rotated, so that one loop was lying oblique to the vertical meridian.

Most patients in group II received a lens with a peg. A lens without peg was chosen if the vitreous face was convex. If any difficulty was encountered in insertion of the implant, no suture was used. Such patients were given miotics postoperatively until synechiae were observed to form between the loops and the iris on pupillary dilatation.

\section{FOLLOW-UP}

Group $I$. These patients were reviewed annually after the first 6 months. ${ }^{4}$ Information about operative and perioperative complications was obtained retrospectively by examination of the patients' hospital notes. The figures for visual acuity at one year were obtained from the follow-up data.

At the time of the most recent follow-up 79 of the patients in this group were still alive. The mean duration of follow-up of these was 7.0 years (range 5 years 2 months to 8 years 10 months). Those outside the district were traced and a report obtained from their ophthalmologist. Those patients remaining within the district who were ambulant (72) were assessed in the clinic by an observer who had not performed the surgery (M.N.). Visual acuity was assessed with a 6-metre Snellen chart, and ocular examination was performed with a Haag-Streit slitlamp. The remaining patients (7) were assessed by domiciliary visits. Of these, one patient was aphasic, and measurement of visual acuity was not possible.
For the other 6 patients only the near acuities were obtained, and these were converted to Snellen equivalents.

Group II. As for group I, operative and perioperative data were obtained retrospectively by examination of the patients' records. The corrected visual acuity, independently assessed by an optician, was obtained from the patients' notes at the visit which most nearly corresponded to one year after operation. Twenty-five of these patients had not reached one year of follow-up, and for these the last recorded corrected visual acuity was used.

\section{ENDOTHELIAL CELL DENSITY ESTIMATIONS}

Group I. Only 10 patients in this group had endothelial cell density measurements performed one month postoperatively by a contact specular microscope developed by Sherrard and fixed-frame cell counting technique. ${ }^{5}$ In 6 of these patients the cell loss was calculated by reference to the preoperative count for the same eye, and in 4 it was calculated by reference to the other (unoperated) eye. ${ }^{6}$

Group II. Fifty-nine consecutive patients in this group received endothelial cell density measurements preoperatively and at one month after surgery. The endothelial cell loss at one month was calculated for them. A Nikon non-contact specular microscope was used by a method previously described. ${ }^{7}$

\section{Results}

Vision. The results for visual acuity one year after surgery are shown in Figs. 2a and $2 b$. One hundred and seventeen patients in group I survived to one year, and of these $102(87 \%)$ had vision of $6 / 12$ or better. Ninety eight patients in group II survived to be followed up postoperatively ( 2 patients died perioperatively). Ninety $(92 \%)$ of the surviving patients in group II had vision of $6 / 12$ or better. The reasons for patients having vision less than $6 / 12$ are shown in Table 1.

The most recent follow-up (mean 7.0 years) of patients in group I revealed a change in the pattern of visual acuity. Fig. 3 shows the results for the 79 surviving patients. 


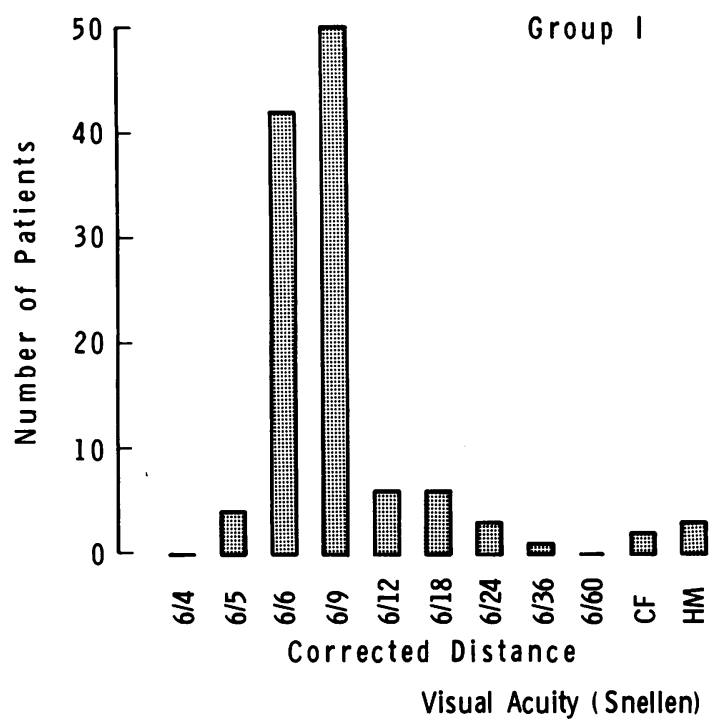

Fig. 2a Corrected visual acuity of 117 surviving patients in group I at l year.

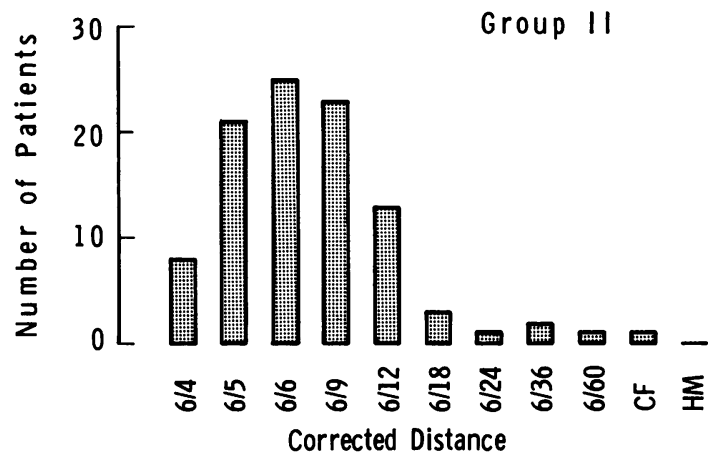

Visual Acuity (Snellen)

Fig. 2b Corrected visual acuity of 98 surviving patients in group II at 1 year.

Table 1 Reasons for visual acuity of worse than $6 / 12$ at one year

\begin{tabular}{lc}
\hline Group I & $(n=127)$ \\
Macular degeneration & 4 \\
Optic atrophy & 3 \\
Retinal detachment & 1 \\
Uveitis & 3 \\
Disc pallor, nystagmus & 1 \\
Unknown & 3 \\
Total & 15 \\
Group II & $(n=100)$ \\
Macular degeneration & 2 \\
Macular oedema & 2 \\
Optic atrophy & 1 \\
Unknown & 3 \\
Total & 8 \\
\hline
\end{tabular}

Table 2 Operative complications

\begin{tabular}{|c|c|c|c|c|}
\hline & \multicolumn{2}{|l|}{$\begin{array}{l}\text { Group I } \\
(n=127)\end{array}$} & \multicolumn{2}{|l|}{$\begin{array}{l}\text { Group II } \\
(n=100)\end{array}$} \\
\hline & Number & $\%$ & Number & $p$ \\
\hline $\begin{array}{l}\text { Lens-endothelial } \\
\text { contact }\end{array}$ & 34 & $26 \cdot 7$ & 8 & $<0.0001$ \\
\hline $\begin{array}{l}\text { Vitreous loss: implan } \\
\text { proceded with }\end{array}$ & 5 & 3.9 & 2 & NS \\
\hline Iridodialysis & 1 & $0 \cdot 8$ & 0 & NS \\
\hline Ruptured capsulc & 0 & 0 & 3 & NS \\
\hline Torn iris & 0 & 0 & 1 & NS \\
\hline
\end{tabular}

NS=Not significant

Complications. The operative complications for the 2 groups are shown in Table 2 and the complications in the first 3 weeks after surgery are shown in Table 3.

Late complications for the patients in group I surviving to the last follow up are listed in Table 4. Patients were recorded as having bullous keratopathy if there was generalised epithelial and stromal oedema associated with poor vision. They were recorded as having corneal oedema if the oedema was epithelial and stromal but did not affect the whole cornea or appreciably reduce visual acuity.

Table 5 gives the reason for poor vision, where known, for patients in group I whose vision was worse than $6 / 12$ at their final follow-up.

Endothelial cell density. The mean reduction in axial endothelial cell density (percentage for both groups) one month after surgery is shown in Table 6.

Table 3 Complications occurring in first 3 weeks after surgery

\begin{tabular}{|c|c|c|c|c|}
\hline \multirow[t]{2}{*}{ Complication } & \multicolumn{2}{|l|}{$\begin{array}{l}\text { Group I } \\
(n=127)\end{array}$} & \multicolumn{2}{|l|}{$\begin{array}{l}\text { Group II } \\
(n=100)\end{array}$} \\
\hline & Number & $\%$ & Number & $p$ \\
\hline \multicolumn{5}{|l|}{$\begin{array}{l}\text { Transient rise in } \\
\text { intraocular }\end{array}$} \\
\hline \multicolumn{5}{|l|}{ Pupil block } \\
\hline glaucoma & 4 & $3 \cdot 1$ & 0 & NS \\
\hline Total wound leak & 6 & $4 \cdot 7$ & 0 & NS \\
\hline \multicolumn{5}{|l|}{ Wound leak with } \\
\hline $\begin{array}{l}\text { Subluxated or } \\
\text { dislocated }\end{array}$ & 3 & $2 \cdot 3$ & 0 & NS \\
\hline intraocular lens & 2 & 1.5 & 1 & NS \\
\hline Hypopyon & 0 & & 6 & $<0 \cdot 05$ \\
\hline \multirow{2}{*}{$\begin{array}{l}\text { Vitreous } \\
\text { haemorrhage } \\
\text { Cystoid macular } \\
\text { oedema }\end{array}$} & 1 & $0 \cdot 8$ & 1 & NS \\
\hline & $\begin{array}{l}0 \\
\text { (not look } \\
\text { for) }\end{array}$ & & 6 & $<0.05$ \\
\hline
\end{tabular}

$\mathrm{AC}=$ anterior chamber . 
Fig. 3 Corrected visual acuity of 79 surviving patients in group I.

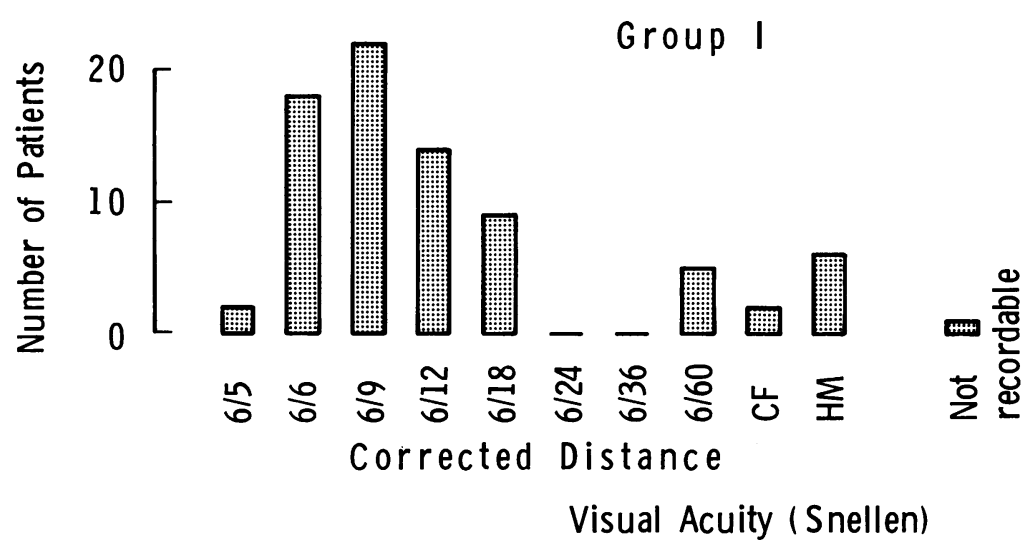

Table 4 Late complications of group I patients $(n=79)$; mean duration of follow-up 7.0 years

\begin{tabular}{llr}
\hline & Number & $\%$ \\
\hline Bullous keratopathy & 6 & $7 \cdot 8$ \\
Corneal oedema & 3 & $3 \cdot 9$ \\
Optic atrophy & 4 & $5 \cdot 2$ \\
Raised intraocular pressure & 8 & $10 \cdot 3$ \\
Retinal detachment & 2 & $2 \cdot 6$ \\
Myopic retinal degencration & 2 & $2 \cdot 6$ \\
Diplopia & 2 & $2 \cdot 6$ \\
Macular degencration & 2 & $2 \cdot 6$ \\
Diabetic retinopathy & 1 & $1 \cdot 3$ \\
Amblyopia & 1 & $1 \cdot 3$ \\
Lens touch to cornca & 1 & $1 \cdot 3$ \\
\hline
\end{tabular}

Table 5 Reasons for visual acuity less than $6 / 12$ at the last review (group I)

\begin{tabular}{lll}
\hline Vision & Reason & Number \\
\hline $6 / 18$ & Bullous kcratopathy & 1 \\
& Glaucoma & 1 \\
& Macular degencration & 2 \\
& Unknown & 5 \\
$6 / 60$ & Bullous kcratopathy & 1 \\
& Amblyopia & 1 \\
& Optic atrophy & 1 \\
Counting fingers & Macular degencration & 2 \\
Hand movements & Bullous keratopathy & 2 \\
& Bullous keratopathy & 2 \\
& Optic atrophy & $3(1$ also \\
& & had retinal \\
& & detach- \\
& & ment) \\
\hline
\end{tabular}

Table 6 Mean corneal endothelial cell loss at one month after surgery

\begin{tabular}{ll}
\hline & Mean cell loss \\
\hline 10 paticnts from group I & $41 \cdot 3 \%$ \\
59 patients from group II & $12 \cdot 2 \%$ \\
Unpaired $t$ test & $t=3 \cdot 69$ \\
& $\mathrm{p}<0 \cdot 001$ \\
\hline
\end{tabular}

\section{Discussion}

In 1976 Kaufman and Katz demonstrated that direct contact with the polymethylmethacrylate of intraocular lenses was highly injurious to the corneal endothelium. ${ }^{8}$ This knowledge resulted in the development of the 'closed chamber' technique described for patients in group II. This change, and increasing surgical experience with lens implantation, are the major differences between the 2 groups. Although a higher proportion of patients in group II received an implant with a fixation peg, the basic implant design was the same in groups I and II.

There are difficulties in matching the 2 groups in this study owing to its retrospective nature. The patients' ages are well matched. The main problem in comparing results arises from differences in the routine of postoperative follow-up, which was more regular in the later group, and in the comprehensiveness of the patients' notes. The records of patients in group II for the perioperative period were far more detailed, and this may have distorted the difference in the frequency of complications. For example, the higher incidence of transiently raised intraocular pressure in group II probably reflects the fact that more pressure readings were recorded postoperatively in these patients.

\section{OPERATIVE COMPLICATIONS}

In spite of the problems of comparison 2 features of the operative complication data stand out and deserve examination. Firstly, the vitreous loss rate fell from $3.9 \%$ in group I to $2.0 \%$ in group II. If the patients who were excluded from the study because vitreous loss prevented lens implantation are also considered, the real reduction of vitreous loss was from $8 \%$ to $2 \%$.

Secondly, $26 \cdot 7 \%$ of patients in the earlier group were recorded as having had some degree of implant -endothelial contact during the insertion 
manoeuvre. In group II, where operative records were more detailed, only $8.0 \%$ of patients were noted to suffer implant-endothelial touch $(p<0 \cdot 0001)$. This suggests that the closed chamber technique can be successfully used with this type of lens implant.

\section{PERIOPERATIVE COMPLICATIONS}

The lower recorded incidence of shallow anterior chamber and wound leakage in group II is interesting (but not significant), as suturing techniques remained largely unchanged. Although the length of the section was shortened in the second group, the number of interrupted sutures used was also reduced. Apposition of the wound edges may have been more precise in the second group, though this is impossible to quantify.

One patient in group II had a painful eye postoperatively associated with hypopyon, which responded to antibiotic and steroid therapy. The other 5 hypopyons recorded in group II were small and transient. The higher incidence of this problem in the later group $(p<0.05)$ may be due to more thorough documentation of these patients in the early postoperative period.

If cystoid macular oedema was suspected on clinical grounds in group II patients, fluorescein angiography was performed. Those patients with a typical angiographic appearance were recorded as having the complication, so the figures reported for group II are a reliable estimate of the incidence of clinical cystoid macular oedema in the first 3 weeks after surgery. Patients in group I did not receive fluorescein angiography in the early postperative period, so the true incidence of cystoid macular oedema is not known for this group. Therefore the apparent difference between the two groups $(p<0.05)$ may be spurious.

\section{VISUAL ACUITY}

The corrected distance visual acuity one year after surgery was slightly better in group II $(92 \%$ with vision $6 / 12$ or better) than in group I $(87 \%)$. These figures parallel those obtained by Jaffe et al., ${ }^{9}$ who measured the proportion of patients achieving vision of $6 / 12$ or better at 34 to 40 months after surgery with intracapsular extraction and Binkhorst lens (86.2\%) and extracapsular extraction and posterior chamber lens $(92 \cdot 4 \%)$. Jaffe's group suggested that the better visual result with the latter lens reflects its superiority. However, our own results suggest that it is possible to achieve similar 'improvements' by retaining the same lens type but changing surgical techniques.

There was a reduction in the proportion of group I patients achieving this level of vision between the one year and the last follow-up (mean 7.0 years), namely, from $87 \%$ to $72 \%$. A similar decline in visual results was reported by Rich in a group of 100 patients who received Federov I lenses with a follow-up of 6 years. ${ }^{2}$
Drews reviewed 90 eyes that had received Medallion lenses, with a mean follow-up of 5.7 years. ${ }^{1}$ The proportion of surviving patients achieving $6 / 12$ vision or better fell from $79 \%$ postoperatively to $66 \%$.

The reasons for poor visual acuity at the long-term follow-up of group I patients are listed in Table 5. Bullous keratopathy was the most important cause (6/22) which could be directly related to the surgical procedure. The increased incidence of corneal oedema with longer follow-up emphasises why shortterm results should not be relied upon in the evaluation of implant procedures. Three years after surgery only 2 eyes in this group had early corneal oedema which did not significantly affect vision. ${ }^{4}$ At the last reported follow-up, 2 years before the present review, 4 cases had bullous keratopathy and 2 more had early corneal oedema. ${ }^{4}$ In the present follow-up 9 patients ( $11.7 \%$ of survivors) had evidence of decompensation of the cornea.

Loss of endothelial cells detected in the early postoperative period is believed to be an indicator of the damaging effect of a surgical procedure on this nonreplicating layer. The cell loss of $41 \cdot 3 \%$ at one month in group I is high, and this reflects the high incidence of recorded implant-endothelial contact. The mean cell loss for patients in the later group was much lower $(12 \cdot 0 \%)(p<0 \cdot 001)$. Olsen reviewed 7 lens implant series and found an endothelial cell loss ranging from $7 \%$ to $62 \% .{ }^{10} \mathrm{Kraff}$ et al. reported a large series with several methods of surgical management of cataract. ${ }^{11}$ They found a mean cell loss of $15.8 \%$ for intracapsular extraction and Choyce anterior chamber implants, and $20 \cdot 2 \%$ for intracapsular extraction and Medallion implants. The mean loss of $12 \cdot 2 \%$ for group II compares favourably with current trends. If endothelial cell loss in the early postoperative period does prove to be a reliable indicator of the long-term danger of corneal oedema, then fewer cases of bullous keratopathy can be expected to arise in group II patients.

It is the intention of this paper to review the longterm follow-up of a group of patients with intraocular lenses and not to promote the use of the Federov I lens. One-plane lenses, either angle supported or for placement in the posterior chamber after extracapsular extraction, do seem to offer advantages in terms of ease of insertion. Long-term results of these lens types are still awaited. Critical evaluation of treatment effects is necessary to bring about improvements in lens implant surgery, and it is important to identify correctly whether improvement was due to a change in lens design or surgical technique, for wrongly attributing the cause of a complication will lead to its repetition. Our study suggests that many of the more serious complications were related to surgery and could be reduced by improvements in technique. 
The authors would like to thank Mr H. Harper, FRCS, for his permission to examine his patients and the ophthalmologists and opticians who examined patients who had moved out of the area. Thanks are also extended to Mrs M. Platts, Mrs P. Brocklesbury, and Mrs J. Cotton for secretarial assistance and to Mr S. Barbour for performing the photography.

\section{References}

1 Drews RC. The Medallion R lens five years later. Am Intra-ocular Implant Soc J 1981; 7: 49-54.

2 Rich W. Intraocular lenses and mobility of the aged. Clinique Ophtalmologique no. 4, 1979. Laboratoires Martinet.

3 Cheng H, Bron AJ, McAvoy J. Serum coating of intraocular lenses and endothelial damage. Trans Ophthalmol Soc UK 1979; 99: 321-3.

4 Cheng H, Law AB, McPherson K, Price NC. Longitudinal study of intraocular lens implants after intracapsular cataract extraction. Trans Ophthalmol Soc UK 1981; 101: 79-83.
5 Sturrock GD, Sherrard ES, Rice NSC. Specular microscopy of the corneal endothelium. Br J Ophthalmol 1978; 62: 809-14.

6 Cheng H, Sturrock GD, Rubinstein B, Bulpitt CJ. Endothelial cell loss and corneal thickness after intracapsular extraction and iris clip lens implantation. Br J Ophthalmol 1977; 61: 785-90.

7 Price NC, Cheng $\mathrm{H}$. Contact and non-contact specular microscopy. Br J Ophthalmol 1981; 65: 568-74.

8 Kaufman HE, Katz J. Endothelial damage from intraocular lens insertion. Invest Ophthalmol visual Sci 1976; 15: 996-1000.

9 Jaffe NS, Clayman HM, Jaffe MS. A comparison of ICCEBinkhorst intraocular lens and ECCE post. chamber IOL 34-40 months post operatively. Am Intra-ocular Implant Soc J 1982; 8: 128-30.

10 Olsen T. Specular microscopic investigations on the corneal endothelium and its involvement in corneal oedema. Acta Ophthalmol (Kbh) 1982; suppl 155.

11 Kraff MC, Sanders DR, Lieberman HL. Specular microscopy in cataract and intraocular lens patients. Arch Ophthalmol 1980; 98: $1782-4$. 